\title{
Safety and ethics of bronchoscopy and endobronchial biopsy in difficult asthma
}

\author{
D Payne, S A McKenzie, S Stacey, D Misra, E Haxby, A Bush
}

\begin{abstract}
Aim-To investigate the safety of bronchoscopy and endobronchial biopsy in children with difficult asthma, and discuss the ethical issues associated with the procedure.

Methods-A three year prospective observational study was performed in two tertiary paediatric respiratory centres specialising in the management of children with difficult asthma. A total of 48 children with difficult asthma and 35 nonasthmatic children were studied.

Results-Flexible bronchoscopy was performed under general anaesthesia in 38 children with difficult asthma, and rigid bronchoscopy was performed in 10, following a two week course of prednisolone. Endobronchial biopsy was performed in 47 patients. Perioperative complications occurred in one asthmatic undergoing flexible bronchoscopy (desaturation) and in two undergoing rigid bronchoscopy (desaturation in one, and bronchospasm and desaturation in one). There were no cases of significant bleeding or pneumothorax among the asthmatics. Flexible bronchoscopy was performed in 35 nonasthmatic patients with a variety of clinical indications. The total number of perioperative complications was greater in the non-asthmatics undergoing flexible bronchoscopy than in the asthmatics (17 complications in 35 children versus one in 38). Fever requiring hospital admission was documented in two asthmatics following bronchoscopy. Four asthmatics reported an increase in symptoms in the week following bronchoscopy.

Conclusions-Bronchoscopy and endobronchial biopsy under general anaesthesia can be performed safely in children with difficult asthma, when the bronchoscopist and anaesthetist are suitably trained. The procedure is acceptable to the families involved.

(Arch Dis Child 2001;84:423-426)
\end{abstract}

Keywords: difficult asthma; endobronchial biopsy; bronchoscopy

Department of

Paediatrics, Royal

London Hospital,

Whitechapel, London

E1 1BB, UK

S A McKenzie

D Misra

Correspondence to:

Dr Bush

a.bush@rbh.nthames.nhs.uk

Accepted 21 November 2000

Some children, with a proven diagnosis of asthma, continue to suffer from worrying morbidity despite high dose treatment, even after intensive efforts to diagnose and treat coexisting disorders, optimise treatment adherence, and reduce the level of exposure to aggravating factors. ${ }^{12}$ Current asthma guidelines recommend the use of regular oral corticosteroids for children with such severe asthma. ${ }^{3}$ This may improve asthma control, but at the risk of adverse effects, particularly growth failure and adrenal suppression. Other treatments, including cyclosporin, methotrexate, intravenous immunoglobulin, or a continuous subcutaneous infusion of terbutaline, may therefore be tried. ${ }^{4-7}$ Each is associated with potentially serious adverse effects and/or a labour intensive regimen. Currently there is little information to help clinicians select the most effective therapy for the individual.

We, and others, have previously recommended that patients who respond poorly to corticosteroids, particularly those in whom unconventional therapies are being considered, should undergo bronchoscopy and endobronchial biopsy. ${ }^{8-10}$ This allows direct inspection of the airways and the opportunity for examination of the underlying pathology. Different phenotypes of difficult asthma appear to exist, ${ }^{11-14}$ and it seems logical to tailor treatment according to information obtained from bronchoscopic evaluation. Biopsy evidence of steroid resistant eosinophilic inflammation in a symptomatic child, accompanied by the typical structural features of basement membrane thickening and increased smooth muscle, confirms the clinical impression of severe asthma, and strengthens the argument for the use of further anti-inflammatory therapy, such as cyclosporin. ${ }^{4}$ Conversely, the absence of the typical pathological features of asthma should lead to a reappraisal of the diagnosis or consideration of therapies aimed at targets other than inflammation, such as a continuous subcutaneous infusion of terbutaline. ${ }^{6}$

For this approach to become accepted, it must be shown to be safe and acceptable to parents and children. This report describes our experience of bronchoscopy and endobronchial biopsy in children with difficult asthma, focusing on the safety and the ethical issues raised. The pathological findings will be described in future reports.

\section{Methods}

SUBJECTS

Patients

We studied children with difficult asthma ${ }^{15}$ who attended the Royal Brompton Hospital (RBH) 
Table 1 Clinical characteristics of children with difficult asthma and non-asthmatic control group

\begin{tabular}{|c|c|c|c|}
\hline & Asthmatic & & Non-asthmatic \\
\hline $\begin{array}{l}\text { Number } \\
\text { Age }(\mathrm{y}) \\
\mathrm{FEV}_{1}(\% \text { predicted })(\mathrm{n}=45) \\
\text { Inhaled budesonide }(\mathrm{mg} / \text { day })(\mathrm{n}=15) \\
\text { Inhaled fluticasone }(\mathrm{mg} / \text { day })(\mathrm{n}=32) \\
\text { Inhaled beclomethasone }(\mathrm{mg} / \text { day })(\mathrm{n}=1) \\
\text { Number on long acting } \beta_{2} \text { agonists } \\
\text { Number on oral prednisolone } \\
\text { Other drugs (currently used or previously tried) }\end{array}$ & $\begin{array}{l}48 \\
10.9(4-17) \\
79(44-104) \\
2.0(0.8-3.2) \\
1.6(1.0-3.0) \\
1.5 \\
40 / 48 \\
18 / 48 \\
\text { Theophylline } \\
\text { Montelukast } \\
\text { Cyclosporin } \\
\text { CSIT† } \\
\text { Cromoglycate } \\
\text { IVIG } \$\end{array}$ & $\begin{array}{l}11 / 48 \\
7 / 48 \\
2 / 48 \\
2 / 48 \\
1 / 48 \\
1 / 48\end{array}$ & $\begin{array}{l}35 \\
9.6(5-15)^{\star}\end{array}$ \\
\hline
\end{tabular}

Data are expressed as mean (range) or proportions (out of 48).

*Not significant.

†Continuous subcutaneous infusion of terbutaline.

$\ddagger$ Intravenous immunogobulin.
Adherence to prednisolone was assessed by simultaneous measurement of serum prednisolone and cortisol, using high performance liquid chromatography. ${ }^{12}{ }^{17}$ Additionally, the treatment aimed to maximise the safety of the procedure. Non-asthmatic patients did not receive prednisolone before bronchoscopy.

ANAESTHESIA

Bronchoscopy was performed in theatre under general anaesthesia, administered by a consultant anaesthetist or specialist registrar under consultant supervision, with a trained operating department assistant. Salbutamol (5 mg via nebuliser) was given to asthmatic patients 30 minutes before induction of anaesthesia. If used, premedication with atropine or glycopyrrolate was given. Intravenous access was obtained in all children. Anaesthesia was induced with intravenous (propofol) or volatile (sevofluorane) agents, and maintained with volatile agents (isofluorane, sevofluorane, or halothane) or intravenous propofol. Carrier gases were oxygen, oxygen/air mixture, or oxygen/nitrous oxide mixture. The choice of muscle relaxant, if used, was between vecuronium, atracurium, rocuronium, or mivacurium. The minimum monitoring included continuous ECG recording and measurements of oxygen saturation, end tidal carbon dioxide, and non-invasive blood pressure. Additional corticosteroid cover was not routinely given. If upper airway pathology, tracheomalacia, or other causes of airway compression were suspected, ${ }^{18}$ the initial examination was performed during flexible bronchoscopy with the patient breathing spontaneously and the bronchoscope passed through a face mask or laryngeal mask. Further examination, and subsequent procedures, were performed via a face mask, laryngeal mask, or endotracheal tube. A size two or three laryngeal mask or $6.5 \mathrm{~mm}$ endotracheal tube was needed to allow adequate ventilation around the bronchoscope. Ventilation was assisted manually, if necessary. During rigid bronchoscopy, the airway was maintained using the bronchoscope. If indicated, airway dynamics were first assessed with the patient breathing spontaneously, before the administration of muscle relaxants. Following bronchoscopy, muscle relaxation was reversed using neostigmine and glycopyrrolate.

\section{FLEXIBLE BRONCHOSCOPY}

Flexible bronchoscopy was performed at the Royal Brompton Hospital. Non-asthmatic patients were bronchoscoped by one of three consultant respiratory paediatricians, using a size $3.6 \mathrm{~mm}$ or $4.9 \mathrm{~mm}$ external diameter bronchoscope (Olympus, UK). All patients with difficult asthma were bronchoscoped by the same consultant (AB), using a $4.9 \mathrm{~mm}$ external diameter bronchoscope with a $2.2 \mathrm{~mm}$ suction channel (Olympus, UK). Bronchoalveolar lavage (BAL) was performed in the right middle lobe, using $10-40 \mathrm{ml}$ aliquots of normal saline, to a maximum of $80 \mathrm{ml}$. Endobronchial biopsy specimens (up to six) were taken from the subcarinae of the right lower lobe, using cupped forceps (FB-19C-1, Olym- 
pus, UK). Each set of forceps was used on a maximum of five patients.

RIGID BRONCHOSCOPY

Rigid bronchoscopy was performed at the Royal London Hospital by a consultant paediatric surgeon (DM). A size $3.5,4.0$, or 5.0 bronchoscope was used. BAL was performed as for flexible bronchoscopy. Up to six endobronchial biopsy specimens were taken from the main carina and the carina between the right middle and lower lobes, using punch biopsy forceps. The same set of forceps was used for all patients.

POSTOPERATIVE CARE

Patients were nursed in the theatre recovery area, with oxygen given by facemask until fully awake. They were then observed on the ward for at least four hours. Oxygen saturation, temperature, heart rate, and respiratory rate were measured every 15 minutes for the first hour, every 30 minutes for the next hour, and hourly subsequently. Chest radiography was not performed routinely. Before discharge children were examined by a clinician. Spirometry was not performed. Patients not normally on regular oral corticosteroids discontinued prednisolone following bronchoscopy. Those taking regular prednisolone as maintenance treatment, had the dose tapered to the maintenance dose. Biopsy/lavage results and subsequent management were discussed at outpatient follow up. At this visit parents and children were asked whether there had been any increase in symptoms following bronchoscopy.

STATISTICAL ANALYSIS

Data were tested for normality using histograms and Kolmogorov-Smirnov testing. Normally distributed data are expressed as mean

Table 3 Details of anaesthetic and bronchoscopic (flexible and rigid) procedures in asthmatic and non-asthmatic patients

\begin{tabular}{|c|c|c|c|}
\hline & $\begin{array}{l}\text { Difficult } \\
\text { Rigid }(n=10)\end{array}$ & $\begin{array}{l}\text { Asthma } \\
\text { Flexible }(n=38)\end{array}$ & $\begin{array}{l}\text { Non-asthma } \\
\text { Flexible }(n=35)\end{array}$ \\
\hline \multicolumn{4}{|l|}{ Induction of anaesthesia } \\
\hline Intravenous & 10 & 33 & 19 \\
\hline Inhalational & 0 & 5 & 16 \\
\hline \multicolumn{4}{|l|}{ Maintenance of anaesthesia } \\
\hline Intravenous & 0 & 2 & 0 \\
\hline Inhalational & 10 & 35 & 33 \\
\hline Both & 0 & 1 & 2 \\
\hline Muscle relaxant used & 10 & 31 & 13 \\
\hline \multicolumn{4}{|l|}{ Type of airway used } \\
\hline Face mask & N/A & 3 & $16 \dagger \ddagger$ \\
\hline Laryngeal mask & N/A & $8^{\star}$ & 8 \\
\hline Intubated & N/A & $28^{\star}$ & $14 \dagger \ddagger$ \\
\hline \multicolumn{4}{|l|}{ Bronchoscopic procedures } \\
\hline Bronchoalveolar lavage & 5 & 38 & 32 \\
\hline Endobronchial biopsy & 10 & 37 & 3 \\
\hline \multicolumn{4}{|l|}{ Complications } \\
\hline Laryngospasm & 0 & 0 & 7 \\
\hline Bronchospasm & 1 & 0 & 0 \\
\hline Apnoea & 0 & 0 & 4 \\
\hline Desaturation $\S$ & 2 & 1 & 6 \\
\hline Bradycardia & 0 & 0 & 0 \\
\hline Bleeding & 0 & 0 & 0 \\
\hline Pneumothorax & 0 & 0 & 0 \\
\hline Total & 3 & 19 & 179 \\
\hline
\end{tabular}

Data are expressed as absolute numbers.

${ }^{\star}$ Includes one patient intubated electively following initial examination via a laryngeal mask. †Includes two patients intubated electively following initial examination via a face mask.

$\ddagger$ Includes one patient intubated as an emergency following initial examination via a face mask.

$\$$ More than $10 \%$ fall below baseline oxygen saturation.

Ip $<0.01$. (range). The age of the asthmatic and the nonasthmatic groups was compared using unpaired $t$ testing. For the two groups undergoing flexible bronchoscopy, the number of complications was compared using $\chi^{2}$ testing. A p value less than 0.05 was considered statistically significant.

\section{Results}

Flexible bronchoscopy was performed in 38 children with difficult asthma, and rigid bronchoscopy was performed in 10 (table 1 ). One family refused to allow their child to undergo bronchoscopy. One family did not give their child prednisolone before bronchoscopy. Table 3 shows details of the anaesthetic and bronchoscopic procedures.

Few perioperative complications occurred among the patients with difficult asthma (table 3). Desaturation occurred on three occasions and was managed by increasing the inspired oxygen and removing the bronchoscope. One episode of desaturation during rigid bronchoscopy was accompanied by bronchospasm, managed, in addition to the above measures, by changing the volatile agent from isofluorane to halothane. There was no significant bleeding and no clinical or radiological instances of pneumothorax. Comparing the two groups undergoing flexible bronchoscopy, there were more perioperative complications in the nonasthmatic group than in the asthmatic group (17 complications in 35 children versus one in $38, \mathrm{p}<0.01$ ), in particular, laryngospasm and apnoea. Postoperatively, two asthmatic children developed a fever of above $38.5^{\circ} \mathrm{C}$ several hours after the procedure. One remained in hospital overnight; the other was discharged, but readmitted to his local hospital the next day. BAL subsequently grew Streptococcus pneumoniae and he remained in hospital for several days. Four asthmatic children reported an increase in symptoms and use of rescue bronchodilator for several days following bronchoscopy (flexible in three; rigid in one).

\section{Discussion}

We consider our report shows that bronchoscopy with BAL and endobronchial biopsy can be performed safely in children with difficult asthma under general anaesthesia, and that the procedure is acceptable to parents and children.

This is the largest series of its kind to have been reported. However, we accept that the number of patients is still small, and that there will always be the potential for morbidity and mortality, however minimal, when performing this procedure. It is important to emphasise that the procedure was undertaken at two centres specialising in the management of children with difficult asthma, by experienced personnel. Although flexible bronchoscopy can be performed under conscious sedation, ${ }^{19}$ we find general anaesthesia more satisfactory. Use of general anaesthesia almost always ensures that the procedure can be completed successfully with minimal discomfort to the child. In experienced hands the risks of general anaesthesia for a child are very small, and the procedure 
can usually be performed as a day case. In a much larger series, routine use of endobronchial biopsy as an additional clinical procedure was without complications. ${ }^{20}$

For flexible bronchoscopy, there were more perioperative complications in the nonasthmatic group than in the asthmatic group. This may be because the asthmatic patients were more likely to be intubated and to have received muscle relaxants. In these patients characterisation of the extent and pattern of airway inflammation was the main purpose of bronchoscopy, rather than assessment of the upper airway and airway dynamics, which was performed more often in the non-asthmatic group. Bronchospasm, which may have been expected to be a significant problem in the asthmatics, was encountered only once during rigid bronchoscopy. The low incidence of complications in the asthmatic group may also be related to the preoperative course of prednisolone. In addition to maximising the safety of the procedure, this, coupled with evidence of satisfactory adherence, allowed us to determine whether there was true steroid resistant eosinophilic inflammation.

Few children reported problems following bronchoscopy. Fever was documented in two patients. This may have occurred in other patients following discharge, but was not reported by parents at follow up. Four patients reported an increase in symptoms in the week following bronchoscopy. We acknowledge that ideally patients should have performed spirometry following the procedure, with a period of peak expiratory flow (PEF) monitoring at home. However, the majority of children had completed a two week PEF diary before bronchoscopy, and we recognise the possibility of diary fatigue. ${ }^{21} \mathrm{~A}$ study of adult asthmatics revealed no difference in PEF rates for two weeks before and after flexible bronchoscopy. ${ }^{22}$ In general the response from the families involved was positive, with most parents grateful for the information provided, particularly if this led to a more logical plan of management. However, this procedure will only be ethical, as well as safe, if it is subsequently shown to contribute to individual patient management.

In this small group of children with difficult asthma, bronchoscopy, BAL, and endobronchial biopsy was performed safely under general anaesthesia, following a two week course of prednisolone, when performed by trained, experienced personnel. These studies should improve our understanding of the pathology of difficult asthma, with the development of more rational prescribing.

Donald Payne is supported by the Royal Brompton Hospital Clinical Research Committee, the PF Trust, and the Cadogan Charity.

1 Balfour-Lynn IM. Difficult asthma: beyond the guidelines. Arch Dis Child 1999;80:201-6.

Connet G. Paediatric evaluation of difficult asthma. Eur Respir Rev 2000;10:40-4.

3 The British Thoracic Society, The National Asthma Campaign, The Royal College of Physicians of London in association with the General Practitioner in Asthma Group, the British Association of Accident and Emergency Medicine, the British Paediatric Respiratory Society, and Medicine, the British Paediatric Respiratory Society, and
the Royal College of Paediatrics and Child Health. The the Royal College of Paediatrics and Child Health. The British Guidelines on Asthma Management 1995.

4 Coren ME, Rosenthal M, Bush A. The use of cyclosporin in corticosteroid dependent asthma. Arch Dis Child 1997;77: $522-3$

5 Guss S, Portnoy J. Methotrexate treatment of severe asthma in children. Pediatrics 1992;89:635-9.

6 O'Driscoll BRC, Ruffles SP, Ayres JG, Cochrane GM. Long term treatment of severe asthma with subcutaneous terbutaline. Br F Dis Chest 1988;82:360-7.

7 Vrugt B, Wilson S, van Velzen E, et al. Effects of high dose intravenous immunoglobulin in two severe corticosteroid insensitive asthmatic patients. Thorax 1997;52:662-4.

8 Payne DNR, Hubbard M, McKenzie SA. Corticosteroid unresponsiveness in asthma: primary or acquired? Pediatr .

9 Thomas PS, Geddes DM, Barnes PJ. Pseudo-steroid resistant asthma. Thorax 1999;54:352-6.

10 Adelroth E. Evaluation of difficult asthma: bronchial biopsies and bronchoalveolar lavage. Eur Respir Rev 2000;10:36-9.

11 ERS Taskforce on difficult/therapy-resistant asthma. Difficult/Therapy-Resistant Asthma: the need for an integrated approach to define clinical phenotypes, evaluate risk factors, understand pathophysiology and find novel therapies. Eur Respir f 1999;13:1198-208.

12 Payne DNR, Wilson NM, James A, et al. Evidence for different subgroups of difficult asthma in children. Thorax (in press).

13 Wenzel SE, Schwartz LB, Langmack EL et al. Evidence that severe asthma can be divided pathologically into two inflammatory subtypes with distinct physiologic and clinical characteristics. Am $f$ Respir Crit Care Med 1999;160:1001-8.

14 Pavord ID, Brightling CE, Woltmann G, Wardlaw AJ. Noneosinophilic corticosteroid unresponsive asthma. Lancet 1999;353:2213-14.

15 Warner JO, Götz M, Landau LI, et al . Management of sthma: a consensus statement. Arch Dis Child 1989;64: 1065-79.

16 Lask B. Psychological factors. In: Silverman M, ed. Childhood asthma and other wheezing disorders. London: Chapman and Hall Medical, 1995:421-8.

17 Payne DNR. Adrenal response to glucocorticoid treatment. Lancet 2000;355:1458.

18 Payne DNR, Lincoln C, Bush A. Lesson of the week: rightsided aortic arch in children with persistent respiratory symptoms. BMF 2000;321:687-8.

19 Tobias JD. Sedation and anesthesia for pediatric bronchoscopy. Curr Opin Pediatr 1997;9:198-206.

20 Bush A, Pohunek P. Brush biopsy and mucosal biopsy. Am $\mathcal{F}$ Respir Crit Care Med 2000;162:S18-22.

21 Redline S, Wright EC, Kattan M, et al. Short-term compliance with peak flow monitoring: results from a study of inner city children with asthm. Pediatr Pulmonol 1996:21: 203-10.

22 Humbert M, Robinson DS, Assoufi B, et al. Safety of fibreoptic bronchoscopy in asthmatic and control subjects and effect on asthma control over two weeks. Thorax 1996;51: 664-9. 